\title{
HEMATOLOGICAL AND BIOCHEMICAL PROFILE IN FEMALE CAMELS (CAMELUS DROMEDARIUS) DURING THE TRANSITION PERIOD
}

\author{
Eman A.Ebissy ${ }^{1}$, Ahmed A. El-Sayed ${ }^{1 *}$, Ragab Hassan Mohamed ${ }^{2}$
}

${ }^{1}$ Department of Animal health and Poultry, Animal and Poultry Production Division, Desert Research Center (DRC), Matariya, Cairo, Egypt, ${ }^{2}$ Theriogenology Department, Faculty of Veterinary Medicine, Aswan University, Aswan, Egypt

${ }^{*}$ Corresponding author, E-mail: decernes@yahoo.com

\begin{abstract}
The aim of the present study was to evaluate the hematological and biochemical alterations in female camels during the transition period. Ten apparently healthy camels were randomly selected and subjected to clinical examination. The investigated camels demonstrated no detectable clinical illness and kept under veterinary supervision throughout the study period. A blood sample was collected from each camel for laboratory investigation before and after 2 and 4 weeks of parturition and at time of parturition. Our findings revealed a significant $(p=0.001)$ high values of neutrophils, $\mathrm{MCH}$ and $\mathrm{MCHC}$ at +14 , and a significant $(p=0.001)$ low values of lymphocyte count at -14 and at time of parturition. The globulin concentration increased significantly $(p=0.029)$ at +28 . For serum phosphorus and magnesium concentrations, their values were significantly $(P<0.05)$ elevated at -14 and +28 , respectively, while enzymatic activity of liver enzymes including aspartate aminotransferase (AST), y-glutamyl transferase (GGT) and alkaline phosphatase $(A L P)$ were significantly $(P<005)$ elevated at +14 , while serum activity of GGT and ALP continued at the same pattern at +28 . For serum glucose and cortisol concentrations, their values were significantly elevated at $(0)$, while serum creatinine concentrations were significantly $(p=0.023)$ decreased at +14 . Estrogen concentration increased significantly at -14 and 0 , but decreased significantly at +14 and +28 . Progesterone concentrations increased significantly at -14 and decreased at $0,+14$ and +28 . Other tested parameters did not differ significantly pre- and post-partum. The data presented in this study could be used as a reference guide for female camels during the transition period.
\end{abstract}

Key words: Biochemistry; camel; hematology; transition period

\section{Introduction}

Dromedary camels are characterized by a seasonal activity and induced ovulators. Reproductive physiology of Arabian dromedary camels has gotten little interest compared to other animal species, especially in relation with changes in blood constituents. Changes in several biochemical parameters have been reprimanded for reproductive disappointments (1).

Severe economic losses can result from suboptimal transition of pregnant animal from the late-pregnancy to lactation; this could probably to impaired production and reproductive performance $(2,3)$. Hence, optimal transition 
requires a comprehensive understanding of biochemical alterations that occurs during the transition period (4).

The transition period, defined as three weeks around the time of calving, is characterized by distinct endocrine alterations that are much more dramatic than at any other time stage of lactation-gestation cycle $(2,5)$. In Egypt, only limited data on serum biochemistry and hematology of one humped camel are available in the literature (6) and most of these literatures encompass limited laboratory measurements (7, $8)$. Therefore, the present study is an attempt to provide an insight into the dynamics of selected haematobiochemical alterations in the transitional one humped camel in order to provide potentially new and useful information about the guidelines for the management strategies during different physiological phases.

\section{Materials and methods}

\section{Animals}

The present study included ten apparently healthy female dromedary camels reared at Mariut Research Station, Desert Research Center, El-Amria, Alexandria, Egypt. Their mean body weight was $415 \mathrm{~kg}$ (range: 313 - $590 \mathrm{~kg}$ ) and their mean ages were 12.6 years (range: 10 -15 years). All procedures were performed in accordance with the guidelines of Desert Research Center (Egypt) and approved by its Ethical Committees. The camels were considered clinically sound on the basis of physical examination of heart, lungs, rumen and intestine and other vital signs $(9,10)$ in tandem with the preliminary findings of hematological examination. Camels were housed in an open yard and fed on a maintenance ration composed of a concentrate mixture including $50 \%$ corn, $47 \%$ barley, $2 \%$ minerals, $1 \%$ salt which given at rate of $3 \mathrm{~kg} / \mathrm{head} /$ day, while Egyptian clover hay (Trifolium alexandrinum) and fresh water were offered ad libitium.

\section{Blood sampling}

Ten milliliter of blood was collected from each animal at $-28,-14,0,+14$ and +28 days of expected date of delivery via jugular vein puncture using vacutainer tube containing anticoagulant (EDTA or sodium fluoride) and without anticoagulant to yield whole blood or serum, respectively. The tubes containing EDTA were used for prompt hematologic examination. The hematological indices included total leucocytes (WBC) and differential leukocyte count (lymphocytes, neutrophils, monocytes, and esinophils), red blood cells (RBC), hemoglobin (HGB), hematocrit, mean erythrocyte volume (MCV), mean corpuscular hemoglobin $(\mathrm{MCH})$, and mean corpuscular hemoglobin concentration (MCHC) which were carried out on automatic blood cell counter (Exigoeos veterinary Hematology system, Boule Medical AB, Sweden). On the other side, tubes containing sodium fluoride were used for quantifying concentrations of glucose which were measured spectrophotometrically using a commercial test kit supplied by Spectrum Egypt (Ref: 250001). The plain tubes were kept at room temperature overnight to be centrifuged at $3000 \mathrm{rpm}$ for 15 minutes. Only clear sera were collected then aliquoted and kept frozen at $-200 \mathrm{C}$ for subsequent biochemical analyses using commercial test kits according to the standard protocols of suppliers. For the total protein, albumen, calcium, phosphorus, magnesium and creatinine, commercial test kits supplied by BioMed Egypt were used (Ref: ALB100250; TP116250; CAL103100; PH123100, MG122050 and CRE 106100), respectively. For AST, ALP, $7 /$ GT and cholesterol, commercial test kits supplied by Spectrum Egypt were used (Ref: AST260001; ALP214001; 7 GT246001 and CHOL230001), respectively. For BUN, commercial test kits supplied by BioScien Egypt were used (Ref: BSU117100). For cortisol and estradiol, commercial test kits supplied by Parameter ${ }^{\mathrm{TM}}$ USA were used (Ref: KGE008B and KGE014), respectively. For Progesterone, commercial test kit supplied by Oxford Biomedical Research USA was used 
(Ref: EA 74). For creatinine kinase, commercial test kit supplied by Bio Chain USA (Ref: Z5030048) was used.

\section{Statistical analysis}

Statistical analyses were carried out using a statistical software program (SPSS, ver.20, Inc., Chicago, USA). Descriptive statistics were performed for all parameters. Repeated measures ANOVA was used to test the effect of physiological status during the transitional period on blood metabolic profile. Results were considered statistically significant at $\mathrm{P}<0.05$.

\section{Results}

An overview of serial measurements of hematological and serum biochemical profile in the studied camels during the transition period was illustrated in Tables $1 \& 2$. Clinically, the investigated animals showed no detectable clinical alterations throughout the study period and remained clinically healthy. All camels demonstrated normal laboring and delivered a single calf without obvious clinical illness.

Table 1 illustrates the hematological variables in examined camels. The total white blood cells revealed non-significant differences $(\mathrm{P}=$ $0.296)$ through the different time points (-28, $14,0,+14$ and +28$)$. Lymphopenia was observed at -14 and 0 time points $(\mathrm{P}=0.001)$ and neutrophilia at +14 and +28 postpartum $(\mathrm{P}=$ 0.001 ). There was no significant difference between Monocyte and eosinophils during the periparturient period $(\mathrm{P}=0.730$ and $\mathrm{P}=0.447$, respectively). There was no significant difference between the red blood cells, haemoglobin, hematocrit and MCV (P>0.05) throughout the periparturient period. On the other side, the
$\mathrm{MCH}$ and $\mathrm{MCHC}$ increased significantly at +14 after parturition $(\mathrm{P}=0.001)$.

Table 2 summarizes the biochemical variables in examined camels. Serum concentrations of the total protein and albumin concentrations did not differ significantly among all the tested time points pre- and post-partum $(\mathrm{P}>0.05)$. However, globulin concentrations were significantly $(\mathrm{P}=0.029)$ increased at +28 . Calcium concentration did not differ significantly among all the tested time-points pre- and post-partum $(\mathrm{P}=0.201)$. While concentrations of serum inorganic phosphorus and magnesium were significantly $(\mathrm{P}=0.004$ and 0.023$)$ increased at -14 and +28 respectively. For serum activity of AST, GGT and ALP, their values showed a significant increase $(P>0.05)$ at +14 . The concentration of ALP and GGT remained also at a significant $(P=0.001)$ high pattern at +28 after parturition. In contrast the serum activity of creatinine kinase did not differ significantly pre- and postpartum $(\mathrm{P}=0.125)$.

Concentrations of serum glucose were significantly $(P=0.001)$ elevated at the time of parturition. The serum concentration of BUN did not show any significance at the tested time points $(\mathrm{P}=0.370)$. However, creatinine concentrations were significantly $(\mathrm{P}=0.023)$ decreased at +14 post-partum. Serum concentration of cortisol showed a significantly $(\mathrm{P}=$ 0.001) elevation at the time of parturition. hand the concentration of serum estrogen was increased significantly at -14 and 0 , but decreased significantly at +14 and $+28(\mathrm{P}=0.001)$. The serum progesterone level increased significantly at -14 and decreased at $0,+14$ and +28 $(P=0.001)$. 
Table 1: Hematological parameters (mean \pm SEM) in female dromedary camels during the periparturient period $(\mathrm{n}=10)$

\begin{tabular}{lllllll}
\hline & -28 & -14 & 0 & +14 & +28 & P value \\
\hline WBC $\left(\times 10^{9} / \mathrm{L}\right)$ & $11.24 \pm 0.49$ & $8.52 \pm 1.29$ & $9.96 \pm 1.22$ & $11.75 \pm 1.65$ & $9.50 \pm 0.68$ & 0.296 \\
$\mathrm{RBC}\left(\times 10^{12} / \mathrm{L}\right)$ & $10.17 \pm 0.71$ & $11.65 \pm 0.25$ & $10.74 \pm 0.42$ & $9.09 \pm 1.23$ & $10.90 \pm 0.44$ & 0.218 \\
$\mathrm{Hb}(\mathrm{g} / \mathrm{dl})$ & $10.98 \pm 0.82$ & $11.64 \pm 0.46$ & $10.62 \pm 0.55$ & $12.30 \pm 0.45$ & $11.64 \pm 0.96$ & 0.414 \\
$\mathrm{PCV} \%$ & $33.70 \pm 1.24$ & $30.56 \pm 1.31$ & $32.10 \pm 1.44$ & $33.00 \pm 1.22$ & $29.98 \pm 1.64$ & 0.319 \\
$\mathrm{MCV}(\mathrm{fL})$ & $31.42 \pm 1.06$ & $30.36 \pm 1.71$ & $30.06 \pm 1.53$ & $30.66 \pm 1.25$ & $28.14 \pm 1.50$ & 0.583 \\
$\mathrm{MCH}(\mathrm{pg})$ & $9.00 \pm 0.61$ & $12.90 \pm 0.78$ & $8.98 \pm 0.54$ & $14.74^{*} \pm 0.53$ & $10.58 \pm 0.46$ & $0.001^{*}$ \\
$\mathrm{MCHC}(\mathrm{g} / \mathrm{dl})$ & $31.95 \pm 3.04$ & $36.74 \pm 2.19$ & $26.65 \pm 0.95$ & $44.38 * \pm 0.24$ & $32.45 \pm 1.71$ & $0.001^{*}$ \\
Lymph $\left(\times 10^{9} / \mathrm{L}\right)$ & $6.69 \pm 0.32$ & $3.01^{*} \pm 0.66$ & $1.92^{*} \pm 0.31$ & $3.69 \pm 0.50$ & $6.16 \pm 0.52$ & $0.001^{*}$ \\
Monocyte $\left(\times 10^{9} / \mathrm{L}\right)$ & $0.28 \pm 0.04$ & $0.31 \pm 0.08$ & $0.25 \pm 0.04$ & $0.23 \pm 0.07$ & $0.19 \pm 0.07$ & 0.730 \\
Neutrophil $\left(\times 10^{9} / \mathrm{L}\right)$ & $3.68 \pm 0.31$ & $3.18 \pm 0.74$ & $5.31 \pm 0.15$ & $8.20^{*} \pm 0.96$ & $5.67^{*} \pm 1.14$ & $0.001^{*}$ \\
Eosinophil $\left(\times 10^{9} / \mathrm{L}\right)$ & $0.25 \pm 0.05$ & $0.19 \pm 0.02$ & $0.26 \pm 0.12$ & $0.33 \pm 0.07$ & $0.21 \pm 0.01$ & 0.447 \\
\hline
\end{tabular}

*Values with an asterisk within the same raw are statistically significant $(\mathrm{P}<0.05)$.

WBC: White blood cells; RBC: Red blood cells; Hb: Hemoglobin; PCV: Packed cell volume; MCV: Mean corpuscular volume; MCH: Mean corpuscular hemoglobin; MCHC: Mean corpuscular hemoglobin concentration; Lymph: Lymphocyte

Table 2: Biochemical parameters (mean \pm SEM) in female dromedary camels during the transition period $(\mathrm{n}=10)$

\begin{tabular}{lllllll}
\hline & -28 & -14 & 0 & +14 & +28 & P value \\
\hline & & & & & & \\
$\mathrm{Ca}(\mathrm{mmol} / \mathrm{l})$ & $1.99 \pm 0.09$ & $2.18 \pm 0.11$ & $2.22 \pm 0.08$ & $2.26 \pm 0.05$ & $2.16 \pm 0.03$ & 0.201 \\
$\mathrm{P}(\mathrm{mmol} / \mathrm{l})$ & $1.76 \pm 0.14$ & $2.07^{*} \pm 0.05$ & $1.70 \pm 0.11$ & $1.38 \pm 0.07$ & $1.76 \pm 0.09$ & $0.004^{*}$ \\
$\mathrm{Mg}(\mathrm{mmol} / \mathrm{l})$ & $1.02 \pm 0.06$ & $1.02 \pm 0.04$ & $1.03 \pm 0.03$ & $1.00 \pm 0.03$ & $1.18^{*} \pm 0.02$ & $0.023^{*}$ \\
$\mathrm{AST}(\mathrm{U} / \mathrm{l})$ & $102.5 \pm 4.11$ & $109.75 \pm 0.85$ & $114.25 \pm 2.39$ & $124.25^{*} \pm 2.17$ & $111.5 \pm 4.99$ & $0.005^{*}$ \\
$\mathrm{ALP}(\mathrm{U} / \mathrm{l})$ & $33.75 \pm 4.21$ & $39.5 \pm 4.99$ & $49.5 \pm 5.8$ & $81.50^{*} \pm 4.09$ & $65.75^{*} \pm 4.71$ & $0.001^{*}$ \\
$\mathrm{GGT}(\mathrm{U} / \mathrm{l})$ & $17.45 \pm 0.77$ & $16.45 \pm 0.84$ & $26.50 \pm 1.71$ & $39.90^{*} \pm 0.95$ & $33.25^{*} \pm 3.92$ & $0.001^{*}$ \\
$\mathrm{CK}(\mathrm{U} / \mathrm{L})$ & $107.25 \pm 3.3$ & $104.75 \pm 2.78$ & $113.75 \pm 1.49$ & $116.00 \pm 1.47$ & $110.75 \pm 2.17$ & 0.125 \\
$\mathrm{Glucose}(\mathrm{mg} / \mathrm{dl})$ & $194.5 \pm 3.4$ & $162.0 \pm 12.86$ & $228.0^{*} \pm 5.21$ & $155.75 \pm 14.6$ & $160.0 \pm 5.18$ & $0.001^{*}$ \\
$\mathrm{TP}(\mathrm{g} / \mathrm{l})$ & $5.62 \pm 0.14$ & $5.51 \pm 0.18$ & $5.92 \pm 0.17$ & $5.66 \pm 0.06$ & $6.07 \pm 0.10$ & 0.156 \\
$\mathrm{Alb}(\mathrm{g} / \mathrm{l})$ & $2.43 \pm 0.09$ & $2.82 \pm 0.04$ & $2.65 \pm 0.19$ & $2.52 \pm 0.04$ & $2.39 \pm 0.11$ & 0.186 \\
Globulin (g/l) & $32.25 \pm 0.81$ & $32.73 \pm 2.19$ & $29.53 \pm 2.10$ & $31.38 \pm 0.58$ & $40.68^{*} \pm 3.89$ & $0.029^{*}$ \\
$\mathrm{BUN}(\mathrm{mmol} / \mathrm{l})$ & $29.15 \pm 5.04$ & $30.25 \pm 6.95$ & $17.09 \pm 0.46$ & $26.50 \pm 4.34$ & $28.28 \pm 5.41$ & 0.370 \\
Creatinine $(\mathrm{mg} / \mathrm{dl})$ & $1.00 \pm 0.06$ & $1.12 \pm 0.04$ & $1.05 \pm 0.11$ & $0.69^{*} \pm 0.11$ & $0.97 \pm 0.07$ & $0.023^{*}$ \\
Cortisol $(\mathrm{ug} / \mathrm{dl})$ & $2.59 \pm 0.32$ & $1.76 \pm 0.13$ & $5.05^{*} \pm 0.66$ & $2.80 \pm 0.59$ & $1.53 \pm 0.14$ & $0.001^{*}$ \\
Progesterone(ng/ml) & $3.86 \pm 0.10$ & $4.73^{*} \pm 0.17$ & $2.76^{*} \pm 0.24$ & $2.41^{*} \pm 0.25$ & $2.41^{*} \pm 0.26$ & $0.001^{*}$ \\
Estrogen (pg/ml) & $202.8 \pm 22.5$ & $303.3^{*} \pm 22.6$ & $657.5^{*} \pm 36.4$ & $126.8^{*} \pm 13.3$ & $102.5^{*} \pm 17.2$ & $0.001^{*}$ \\
\hline
\end{tabular}

*Values with an asterisk within the same raw are statistically significant $(\mathrm{P}<0.05)$.

Ca: Calcium; Ph: Phosphorus; Mg: Magnesium; AST: aspartate aminotransferase; TP: Total protein; Alb: Albumen; ALP: Alkaline phosphatase; GGT: Gamma Glutamyl Transferase; BUN: Blood Urea Nitrogen; CK: Creatinine Kinase

\section{Discussion}

The transition period in dromedary camels has gained very little attention relative to that of dairy cattle although a limited report has exist in guanacos (Lama guanicoe) and in the llama (Lama glama) $(7,8)$. Indeed, laboratory profiling, can detect sick animals, and help identify herds at a potential risk of having metabolic and reproductive ailments. To fulfill this research gap, we sampled ten female pregnant dromedary camels at four weeks prior to the anticipated time of parturition to four weeks after calving. In this study, the most noticeable hematological changes in the female camels during the transition period were neutrophilia which was occurred at +14 and +28 . This finding was in accordance with that reported previously in transition camel (11) and in cattle during the periparturient period (12). The authors 
attributed such finding to stress being associated with parturition and the beginning of lactation stage.

The current study revealed that the serum concentration of calcium did not show significance pre- and post-partum. This finding was in agreement with that previously given in camel $(11,13)$ but away from that reported by other researchers $(14,15)$ who found lower calcium levels at the end of pregnancy in dromedary camel and buffaloes, respectively. The authors attributed such findings to the impairment of absorption of these metabolites from the alimentary tract and to the excessive losses through urine, colostrum.

In the current study, there was a significant increase in the serum phosphorus level prepartum and declined thereafter. This finding was in constant with that given by (11) in camel and that reported in buffalo (15) who found lower phosphorus levels during early stage of lactation in buffaloes. The authors attributed such finding as a result of the important role of phosphorus in the colostrums synthesis (16) and enhanced carbohydrate metabolism.

Magnesium plays a vital role during the metabolism of carbohydrates, lipids, nucleic acids and proteins. In present investigation, there was a significant increase in the serum magnesium at +28 days postpartum. Our finding was similar to that obtained by (11) in transition camel and by (17) in Ongole cows but away from that, reported by (18) who recorded lowered magnesium mean values in cattle and buffalo during early lactation.

The alterations of serum globulin, but not albumin, could be resulted from the formation of immunoglobulins. This finding was noticed to be in harmony with that given in transition camel (11) and in dairy cows (5), while the decrease of serum albumin levels could be associated with hepatic diseases. This finding is in accordance with previous reports in transition camel $(11,21)$. However, in this study its reduction was not significant.

In the present study, there was a significant decrease in the serum creatinine level at +14 days postpartum. This finding is in constant with that reported previously in periparturient camel (11) and in transition cattle (12). The creatinine level (marker of kidney function) is dependent on total body content of creatinine, which in turn depends on the dietary intake, rate of synthesis of creatinine, and muscle mass (19). The creatinine concentrations in the prepartum period were higher than those in postpartum. This finding is line with that reported previously (20) at late gestation camel who found high creatinine levels in dromedary camels during late gestation. The authors attributed such finding to high requirement of protein and lower rate of kidney elimination associated with late stage of pregnancy (13).

In the current study, there was a significant increase in the serum activity of AST, GGT and ALP at +14 . The serum activity of GGT and ALP remained also at a significant $(\mathrm{P}=0.001)$ high pattern at +28 after parturition. Our findings were similar to that obtained in periparturient camel (11) and in dairy cows (5) but unlike to that given in late pregnant dromedary camels (22) and in pregnant mares (23) who reported a significant decrease in the GGT activity in the pregnant camels and in pregnant mare. It has been suggested that GGT is involved in the metabolism of glutathione to maintain antioxidative status of the entire body (24).

The increased concentration of glucose at parturition (0) may be due to the stress of parturition and coincide with elevation of cortisol at this period. This finding was in agreement with that given previously in transition camel (11) and in dairy cows (5) but unlike to that given by other researchers $(25,26)$ in peri-parturient dromedary camel who had found a significant decrease of glucose concentration before parturition compared to the period after. In the former study, the authors attributed such finding to the effect of gestational state on glucose level.

The current study revealed that, the serum level of BUN did not show any significance pre- and post-partum changes. This finding was in agreement with that given in transition camel (11) but in contrary with that reported in pregnancy of dromedary camels (22). The authors reported a significant increase of serum BUN in pregnant camels. The authors attributed such 
finding as a result of protein catabolism and high requirement for energy by pregnant camels during the late pregnancy period resulting to an increase in BUN level.

Our findings demonstrated that concentration of serum cortisol was significantly increased at parturition (0) which may be due to stress of parturition due to the increase in the concentration of ACTH secretion from the foetal pituitary $(11,27,28,29)$.

The serum activity of estrogen was elevated at -14 and reached its maximum peak at the time of parturition and declined thereafter. Such elevation of serum estrogen is considered as physiological response to potentiate uterine contraction during parturition. These findings were in agreement with that given by $(11,30$, $31,32)$ in camel and $(33,34)$ in goat. The authors attributed the dropped of maternal estrogen postpartum to that the estrogen measured in pregnant camel was fetoplacental in origin. On the other side, serum activity of progesterone was lowered at the time of parturition and the time onward (i.e. 0 to +28 ) which was considered as a physiological response in order to remove the corpus luteum of pregnancy. These findings were in agreement with that given by $(11,33,34)$.

\section{Conclusion}

The data herein demonstrated a profound haematobiochemical alteration which could be considered as a feature of transition period in peripartum camels. Such alterations are not necessarily indicative of disease but could reflect a physiological variation and could be used as a reference guide for she-camels during the periparturient period.

\section{Conflict of interest}

The authors declare that they have no conflict of interest.

\section{Acknowledgments}

The authors acknowledge the staff members of Animal Health and Poultry Department, Desert Research Center, Egypt.

\section{References}

1. Zarrouk A, Souilem O, Beckers JF. Actualitéssur la reproduction chez la female dromedary (Camelusdromedarius): Revue Elev Med Vét Pays Tropi 2003; 56: 95-102.

2. Drackley JR. Biology of dairy cows during the transition period: The final frontier. J Dairy Sci 1999; 82:2259-73

3. Overton TR, Waldron MR. Nutritional management of transition dairy cows: Strategies to optimise metabolic health. J Dairy Sci 2004; 87 (E Suppl.), E105-19.

4. Guo J, Peters RR, Kohn RA. Effect of a transition diet on production performance and metabolism in periparturient dairy cows. J Dairy Sci2007;90:5247-58.

5. Tharwat M, Oikawa S ,Buczinski S. Ultrasonographic prediction of hepatic fat content in dairy cows during the transition period. J Vet Sci Technol 2012; 3:1.

6. Osman TE, Al-Busadah KA. Effects of age and lactation on some biochemical constituents of camel blood in Saudi Arabia.Camel Practice and Research 2000; 2: 149-52.

7. Leon JB, Smith BB, TimmKI, LeCren G. Endocrine changes during pregnancy, parturition and the early post-partum period in the llama (Lama glama). Journal of Reproduction and Fertility 1990; 88: 503-11.

8. Riveros JL, Urquieta B, Bonacic C, Hoffmann B, Bas F, Schuler G. Endocrine changes during pregnancy, parturition and post-partum in guanacos (Lama guanicoe). Animal Reproduction Science 2009; 116: 318-25.

9-Rosenberger G. Die KlinischeUntersuchung des Rindes. $3^{\text {rd }}$ edn. Berlin and Munich, Paul Parey 1990

10. Radostits OM, Mayhew IG, Houston DM. Veterinary Clinical Examination and Diagnosis. W.B. Saunders, London 2000

11. Tharwat M, Ali A, Al-Sobayil F, Selim L,Abbas H.Hematobiochemical profile in female camels (Camelusdromedarius) during the periparturient period. Journal of Camel Practice and Research. 2015; 22 (1): 101-6.

12. El-Ghoul W, Hofmann W, Khamis Y,Hassanein A. Relationship between claw disorders and the peripartal period in dairy cows. PraktTierarzt 2000; 81:862-8.

13. Omidi A, Sajedi ZH, MontazerTorbati MB, Mostafai M. Metabolic profile of pregnant, non- 
pregnant and male two humped camels (Camelusbactrianus) of Iran. Iran. J. Vet. Med 2014; 8: 23542.

14. Eltohamy MM, Salama A, Yousef AA. Blood constituents in relation to the reproductive state in she-camel (Camelusdromedarius). Beitr Trop. LandwirtschVeterinarmed. 1986; 24:425--0

15. Hagawane SD, Shinde SB, Rajguru DN. Haematological and Blood Biochemical Profile in Lactating Buffaloes in and around Parbhani city. Veterinary World, 2009; 2(12):467-69

16. Rook JAF, Thomas PC. Nutritional physiology of farm animals Ed 1.Longman Inc. New York 1983.

17. Rao DG. Studies on some biochemical constituents of blood in Ongole cows. Ind. Vet. J. 1981; $870-3$.

18. Gupta GC, Rai P. A note on biochemical profile in pre and post-partum states in cattle and buffaloes. Indian J Vet Med. 1987; 7: 45-6

19. Patel SS, Molnar MZ, Tayek JA, Noori N, Benner D, Heymsfield S, Kopple JD, Kovesdy CP, Kalantar-Zadeh K. Serum creatinine as a marker of muscle mass in chronic kidney diseases: results of a cross- sectional study and review of literature. J CachexiaSarcopenia Muscle.2013;4: 19-29.

20. Yousef FA, Karima GMM, Mohamed MMK, Nawito MF, AbdelRazik AMA. Histomorphometry aspect of thyroid gland and biochemical profile in pregnant and non-pregnant dromedary camels. African Journal of Biotechnology. 2016; 15 (10): 370--5.

21. Nehra V, Angulo P, Buchman AL, Lindor KD. Nutritional and metabolic considerations in the etiology of nonalcoholic steatohepatitis.Digestive Diseases and Sciences2001; 46:2347-52.

22. Omidi A, Fathi MH,Asiaban M. Elevated levels of blood urea nitrogen and creatinine in the last trimester of pregnancy of dromedary camels (Camelusdromedarius). Iranian Journal of Veterinary Medicine.2015;9 (4): 249-55.

23. Milinković-Tur S, Peric V, Stojevic Z, ZdelarTuk M, Pirsljin J. Concentrations of total proteins and albumins, and AST, ALT and GGT activities in the blood plasma of mares during pregnancy and early lactation. Veterinarski Arhiv 2005; 75: 195-202.
24. Chen Y, Dong H, Thompson DC, Shertzer HG, Nebert DW, Vasiliou V.Gluta- thione defense mechanism in liver injury: in- sights from animal models. Food ChemToxi- col. 2013;60: 38-44

25. Kelanmer R, Antoine-Moussiaux N, AbuMedian AAK, Hanzen CH, Kaidi R. Effect of nutrition on reproductive performance during the peripartum period of female camel (Camelus-dromedarius) in Algeria. J Anim Vet Advan 2018; 14 (7): 192-6.

26. Saeed A, Khan IA, Hussein MM. Change in biochemical profile of pregnant camels (Camelusdromedarius) at term. Comparative Clinical Pathology.2009; 18: 139-43.

27. Suganya G, Gomathy VS. Hormone profile of Tellicherry goats during periparturient period.Tamilnadu. Journal of Veterinary and Animal Sciences 2009;5: 211-21.

28. Suganya G, Leela V, Viswanathan S, David BP. Circulating levels of cortisol during pregnancy, parturition and post-partum periods in goats. Indian Veterinary Journal 2000;77: 202-4.

29. Arthur GH, Noakes DE, Pearson H. Veterinary Reproduction and Obstetrics, 6th edn, ELBS Publishers, London, UK. pp 133.1989.

30. Ayoub A, EL-Khouly AA, Mohamed TM. Some hematological and biochemical parameters and steroid hormone in the one- humped camel during the different physiological conditions. Emir $\mathbf{J}$ Agric. Sci. 2003; 15 (1): 44-55.

31. Zhao XXY, Chen BX. Serum progesterone and $17 \beta$ estradiol concentration during pregnancy of Bactrian camel (Camelusbactrianus). Theriogenology.1998;50: 595-604.

32. Skidmore JA, Billah M, Allen WR. Pattern of hormone secretions throughout pregnancy in the one- humped camel (camels dromedaries). Reprod. Fertil.Dev.1996; 8:863-9.

33. Alwan AF, Amin FAM, Ibrahim NS. Blood progesterone and oestrogen hormones level during pregnancy and after birth in Iraqi sheep and goat. Basrah Journal of Veterinary Research 2010; 10 : 153.

34. Khan JR, Ludri RS. Hormone profile of crossbred goats during the periparturient period. Tropical Animal Health and Production 2002; 34:151-62. 